\title{
Vitamina C: uma proposta para Abordagem de Funções Orgânicas no ensino médio
}

\author{
Jéssica Guerreiro Martins \\ Bruno Rafael Machado \\ Alessandra Machado Baron \\ Lilian Tatiani Dusman Tonin
}

\begin{abstract}
Resumo
Este trabalho foi desenvolvido por bolsistas do PIBID Química UTFPR Apucarana. Foi escolhida a vitamina $C$ como tema de estudo para ensinar funções orgânicas e a proposta foi estruturada nos três momentos pedagógicos de Delizoicov. Foi realizada uma problematização inicial sobre a Vitamina C, levantando questões sobre o conhecimento prévio dos alunos. No segundo momento, foi apresentado um vídeo e discutido o assunto, havendo uma interação professor-aluno e aluno-aluno. No terceiro momento os alunos realizaram um experimento para comparar o teor de vitamina $\mathrm{C}$ em diferentes frutas. Este foi aplicado de forma problematizada, direcionando os estudantes a levantar hipóteses e sugerir explicações para os eventos observados. Após as explicações científicas os alunos responderam um questionário sobre a prática, demonstrando um bom entendimento do assunto. Os estudantes responderam novamente o questionário inicial, demonstrando evolução de seus conceitos, confirmando que a metodologia mostrou-se eficiente no ensino de funções orgânicas.
\end{abstract}

Palavras-chave: Ensino de Química, Problematização, Momentos pedagógicos.

\begin{abstract}
This work was developed by fellows PIBID Chemistry UTFPR Apucarana. Vitamin $C$ was chosen as the subject of study to teach organic functions and the proposal was structured in the three pedagogical moments of Delizoicov. An initial questioning was conducted on vitamin $C$, raising questions about the students' prior knowledge. In the second moment, was presented a video and discussed the matter, with a teacher-student and student-student interaction. In the third moment the students conducted an experiment to compare the vitamin C content in different fruits. This was applied to problematic way, directing students to make hypotheses and suggest explanations for the observed events. After scientific explanations the students answered a questionnaire about the practice, showing a good understanding of the subject. Students completed the initial questionnaire again demonstrating evolution of its concepts, confirming that the method proved to be effective in teaching organic functions.
\end{abstract}

Keywords: Chemistry Teaching, Problematizing, Pedagogical moments. 


\section{Introdução}

O ensino de Química muitas vezes é tratado de forma distante da realidade dos alunos. 0 desafio de trazer essa ciência para perto do educando e mostrar que ela está inserida a sua volta, tem atribuído discussões, novas abordagens de materiais alternativos e metodologias no ensino de Química. Segundo Maldaner (2000), são necessárias mudanças principalmente na abordagem dos conteúdos de química.

A aprendizagem significativa possui como relação à interação cognitiva entre o novo conhecimento e o conhecimento prévio do educando, através de um processo não arbitrário, no qual o conhecimento absorvido adquire significados e o conhecimento prévio amplia-se, ou seja, torna-se mais elaborado. Este tipo de aprendizagem se opõe a aprendizagem mecânica, caracterizada pela memorização das informações obtidas não possuindo correlação com o cotidiano dos alunos (MOREIRA e MASINI, 2006).

A atividade experimental constitui um dos aspectos essenciais no processo de ensinoaprendizagem de ciências, estreitando o elo entre motivação e aprendizagem (CARRASCOSA et al., 2006). Para que as aulas experimentais transmitam significativamente o conteúdo aos alunos, estas não podem ser ministradas através de uma "receita de bolo", mas sim de maneira investigativa, no qual os educandos tenham a possibilidade de testar hipóteses, empregando seus conhecimentos prévios, pois este é o inspirador para a desenvoltura de uma aprendizagem significativa (GUIMARÃES, 2009).

A experimentação problematizadora, consiste em um papel auxiliador na atividade à docência, e vai além da experimentação investigativa, pois propõe a leitura, a escrita e a fala como aspectos indissociáveis da discussão conceitual dos experimentos. Possibilita o enriquecimento do processo de ensino, tanto na estimulação, como para dar significado ao conhecimento. Impõe novas metodologias que facilitem o processo de ensino aprendizagem, o que possibilita uma evolução tanto no aspecto macroscópico como no microscópico. Propicia aos alunos a possibilidade de realizar registros, discutir, avaliar hipóteses e sugerir explicações (FRANCISCO Jr, FERREIRA, HARTWIG, 2008).

Quando aliada aos três momentos pedagógicos de Delizoicov, o ensino deve partir de um tema gerador presente no cotidiano dos alunos, e, diante de um problema a ser resolvido. Requer a comunicação, o reconhecimento dos saberes prévios, o questionamento, na abordagem conceitual da temática aplicada. Assim o aluno deve ser capaz de responder a questão inicial, compreender e resolver situações que se apresentem em novos contextos, resultando numa aprendizagem significativa (FRANCISCO Jr, FERREIRA, HARTWIG, 2008).

Os momentos pedagógicos de Delizoicov consistem em três etapas: a problematização inicial, organização do conhecimento e a aplicação do conhecimento. A problematização inicial refere-se à abordagem a situações do dia-a-dia dos alunos, na introdução de conhecimentos 
teóricos específicos, para que possam ser interpretadas. Após a explanação, o conhecimento é problematizado na forma de questões, sendo propostas individualmente ou em pequenos grupos, e posteriormente com todos os educandos. Busca-se unir o conteúdo químico com situações reais que os docentes conhecem ou presenciam, porém não interpretem corretamente por falta de conhecimentos científicos específicos (DELIZOICOV e ANGOTTI, 1990; DELIZOICOV, ANGOTTI, PERNAMBUCO, 2009).

Ao organizar as discussões, o professor deve ter como objetivo os questionamentos propostos pelos alunos mediante aos seus posicionamentos sobre o assunto, com intuito de fazêlos refletir sobre explicações contraditórias e os limites de seus conhecimentos expressados, estabelecendo uma comparação ao conhecimento científico necessário para interpretação do fenômeno. Nesse segundo momento, os conhecimentos prévios dos alunos juntamente com os conhecimentos que foram introduzidos pelo professor devem ser estudados de maneira sistematizada, sendo possível a utilização de diversos recursos: como áudio, vídeo, experimentos, dentre outros, no intuito de almejar o desempenho do papel formativo e construtivo na absorção do conhecimento (DELIZOICOV e ANGOTTI, 1990; DELIZOICOV, ANGOTTI, PERNAMBUCO, 2009).

O último momento consiste na aplicação do conhecimento, que utiliza os saberes adquiridos nas etapas anteriores para analisar, interpretar e apresentar respostas a novas situações. Várias atividades podem ser utilizadas na busca da generalização do conhecimento, no intuído de fazer com que os alunos apliquem o conhecimento adquirido em novas situações (DELIZOICOV e ANGOTTI, 1990; DELIZOICOV, ANGOTTI, PERNAMBUCO, 2009).

Este trabalho apresenta a aplicação e os resultados em relação à aprendizagem dos estudantes, de uma proposta de ensino do tema funções orgânicos estruturada nos três momentos pedagógicos de Delizoicov e utilizando um experimento problematizado sobre a vitamina C.

\section{Metodologia}

O trabalho foi desenvolvido por dois bolsistas do Programa Institucional de Iniciação à Docência (PIBID) - Licenciatura em Química - em parceria com uma das supervisoras envolvidas no projeto. A proposta foi aplicada em uma turma de alunos do terceiro ano do ensino médio do Colégio Estadual Polivalente de Apucarana, parceiro do projeto. A atividade foi aplicada no primeiro semestre de 2014 e foi desenvolvida na sala de aula e no laboratório do Colégio.

A proposta foi dividida em três etapas: na primeira, a problematização inicial, foi solicitado aos alunos que respondessem por escrito a um questionário inicial, com perguntas relacionadas à temática Vitamina C (Quadro 1). As questões foram respondidas em sala de aula. Os alunos foram orientados a responderem individualmente, em um tempo de 15 minutos 
Quadro 1 - Questionário inicial aplicado na problematização inicial

\begin{tabular}{|l|}
\multicolumn{1}{|c|}{ Questionário inicial } \\
\hline 1) O que é vitamina C? \\
2) Onde a vitamina C está presente? \\
3) Qual a importância da vitamina C em seu organismo? \\
4) Na sua opinião, quais funções orgânicas estão presentes na molécula da vitamina C?
\end{tabular}

Na segunda etapa, a organização do conhecimento, foi exibido na televisão da sala de aula, o vídeo "Por que a vitamina C é tão importante para o nosso corpo?" (BORGES, 2013), contendo informações relacionadas à temática. $O$ vídeo foi editado pelos bolsistas, para uma abordagem direcionada ao tema. Durante a apresentação do vídeo foram explicados aos alunos, de forma contextualizada, a presença desta vitamina em diversas frutas, legumes e verduras, destacando suas propriedades e sua importância para o organismo humano quando consumidas. Além disso, foram desenvolvidos alguns conceitos científicos necessários para o entendimento de tema, com destaque para sua nomenclatura e reação de oxidação, que permite a ação deste composto em nosso organismo.

Em seguida fez-se uma revisão das funções orgânicas do ácido ascórbico e de outras substâncias que estão presentes em algumas frutas que foram apresentadas no vídeo. Nesta etapa, os bolsistas destacaram e questionaram os alunos sobre os grupos funcionais presentes nestas moléculas. Esta etapa foi realizada em uma aula de 50 minutos.

A terceira etapa, aplicação do conhecimento, consistiu na realização de um experimento problematizado relacionado à temática. O experimento escolhido para ser problematizado encontra-se descrito na literatura e tem como título: À procura da Vitamina C (SILVA, FERREIRA, SILVA, 1995). Antes de iniciar, os alunos foram orientados em relação às vidrarias e reagentes, $e$ ao objetivo da prática.

Segue detalhes do procedimento experimental:

Colocou-se $200 \mathrm{~mL}$ de água destilada em um béquer de $500 \mathrm{~mL}$ e aqueceu-se este líquido utilizando-se uma fonte de calor até uma temperatura próxima a 50 $\mathrm{C}$, sendo acompanhado por um termômetro; após o aquecimento, colocou-se uma colher de chá cheia de amido de milho na água aquecida, e agitou-se a mistura até que atingisse a temperatura ambiente; em um béquer de 1 litro, contendo aproximadamente $500 \mathrm{~mL}$ de água filtrada, foi dissolvido um comprimido efervescente de vitamina $\mathrm{C}$ e completou-se o volume até $1 \mathrm{~L}$; separou-se $200 \mathrm{~mL}$ da solução anterior e aqueceu-se até a fervura. 
Os alunos escolheram quatro frutas para serem testadas: morango, laranja, banana e uva. Preparou-se o suco dessas frutas; numeraram-se sete béqueres de vidro; adicionou-se a estes béqueres $20 \mathrm{~mL}$ da solução de amido de milho; no béquer 1, deixou-se somente a mistura de amido e água (branco); ao béquer 2 adicionou-se $20 \mathrm{~mL}$ da solução de vitamina C; no 3, $20 \mathrm{~mL}$ da solução de vitamina $C$ fervida e, a cada um dos béqueres 4, 5, 6 e 7 adicionou-se $20 \mathrm{~mL}$ dos sucos. Após esta etapa, adicionou-se, gota a gota, a solução de iodo nos sete béqueres, agitando-se constantemente, até o aparecimento de uma coloração azul.

Durante o experimento os alunos anotaram suas observações no Quadro 2. Foram aplicadas outras questões envolvendo o experimento, como ilustrado no Quadro 3.

Quadro 2. Anotações referentes ao experimento à procura da vitamina $C$.

\begin{tabular}{|l|l|}
\hline Béquer & Volume de iodo adicionado $(\mathrm{mL})$ \\
\hline & \\
\hline & \\
\hline & \\
\hline & \\
\hline & \\
\hline & \\
\hline
\end{tabular}

Quadro 3. Questionário final aplicado na aplicação do conhecimento

\section{Questionário final}

1) O que ocorreu quando se adicionou a solução de iodo à solução contendo amido (béquer 1)?

2) O que ocorreu quando se adicionou a solução de iodo à solução contendo amido + sucos?

3) Qual das amostras você acha que contem maior quantidade de vitamina C? Por quê?

4) Em relação à amostra fervida, ocorreu perda de vitamina C?

5) A partir dos compostos estudados, identifique as funções orgânicas presentes nas estruturas apresentadas na Figura 1. 
Os alunos receberam o procedimento em folhas impressas, para anotarem os resultados e responder as questões propostas. Ao final, os estudantes responderam novamente as questões do questionário inicial (Quadro 1).

Após a aplicação da proposta, os dados foram analisados e serão relatados no item a seguir.

\section{Resultado e Discussão}

O presente trabalho foi aplicado em uma turma do terceiro ano do Ensino Médio, do Colégio Estadual Polivalente de Apucarana. A proposta é fazer com que os alunos compreendam as funções orgânicas através da estrutura da vitamina $C$ e de alguns compostos presentes em algumas frutas.

Para a análise dos dados obtidos, não serão transcritas todas as respostas, sendo selecionadas algumas que serão analisadas mais detalhadamente, e que representam a ideia geral da turma.

A fim de conhecer suas concepções sobre a vitamina C, foi aplicado o questionário inicial (Quadro 1). Esta etapa contou com a participação de $100 \%$ da turma (26 alunos). Na primeira questão, nenhum dos estudantes mencionou que a vitamina $\mathrm{C}$ é o nome usual do ácido ascórbico, contudo $54 \%$ dos estudantes registraram sua importância para nossa saúde. Segue algumas respostas:

Estudante 1: "Na minha opinião vitamina $C$ é um nutriente importante para o desenvolvimento humano. E é uma vitamina natural"

Estudante 5: "É um nutriente essencial necessário para várias funções metabólicas"

Estudante 6: "Componente que ajuda no organismo, na proteção"

Estudante 8: "É uma vitamina que ajuda na imunidade"

Na segunda questão, $100 \%$ dos estudantes citaram frutas e legumes como fontes de vitamina C:

Estudante 2: "Laranja, acerola"

Estudante 7: "Nas laranjas, tangerinas, cenoura, em frutas e legumes de coloração alaranjada"

Estudante 20: "Nas frutas que são mais ácidas"

Na terceira questão $96 \%$ dos discentes descreveram a importância da vitamina C em nosso organismo de maneira correta, demonstrando que os mesmos apresentam uma ideia inicial sobre a vitamina C. Algumas respostas foram:

R. B. E. C. T., vol 8, Ed. Sinect, jan-abr.2015 ISSN - 1982-873X 
Estudante 6: "Ajuda no sistema imunológico, no cabelo, na unha"

Estudante 7: "Ajuda na imunidade"

Estudante 8: "Ajuda na prevenção de doenças (gripes) e na imunidade"

Estudante 12: "Aumenta a resistência do organismo"

A quarta questão necessitava que o aluno conhecesse a molécula de vitamina $\mathrm{C}$ para responder corretamente quais as funções orgânicas presentes. Nenhum dos alunos respondeu corretamente, demonstrando não conhecer sua estrutura. $62 \%$ responderam alguma função orgânica; $19 \%$ incluíram elementos químicos em suas respostas, demonstrando não saber diferenciar uma função orgânica de um elemento químico; e os outros 19\% responderam de forma incorreta (falando da importância), demonstrando total falta de atenção com a pergunta ou não sabiam responder. Segue algumas respostas:

Estudante : "ajuda evitar a gripe"

Estudante 9: "cálcio, ferro, proteína"

Estudante 14: "cloreto de ácido, amidas"

Estudante 19: "Ácido carboxílico"

Estudante 23: "éster e éter"

Apesar da vitamina C ser um tema de grande conhecimento popular, sua estrutura química não é conhecida pelos estudantes. O questionário serviu como base para identificar os conhecimentos prévios dos alunos, e a partir daí inserir o conhecimento científico, buscando não limitar-se ao simples fornecimento de informações.

Partiu-se então para o segundo momento pedagógico, a organização do conhecimento. As questões do primeiro momento direcionaram as discussões que promoveram o diálogo entre professor-aluno e aluno-aluno durante a abordagem dos tópicos de química. Para contribuir com o desenvolvimento desta etapa, foi apresentado o vídeo e foi utilizado o quadro de giz para as explicações científicas sobe o tema. Os bolsistas utilizaram os erros dos alunos na quarta questão para abordarem as funções orgânicas. Assim, além das funções presentes na estrutura do ácido ascórbico (álcool, éster e enol), foram estudadas outras citadas pelos estudantes (ácido carboxílicos, aminas, éter, cloreto de ácido, amida). Ao final desta aula, foi solicitado que os alunos escolhessem quatro frutas que eles acreditavam ter vitamina $C$, para serem estudadas na próxima aula.

No terceiro momento pedagógico, a aplicação do conhecimento, os alunos fizeram o experimento de comparação da quantidade de vitamina $\mathrm{C}$ em diferentes frutas, comparando com a vitamina $C$ comercial e a possível influência da temperatura em sua estabilidade. Participarem 
desta etapa 25 alunos (96\% da turma). Foi lançado a desafio: "Vamos descobrir qual das frutas que a turma escolheu têm maior quantidade de vitamina $C^{\prime \prime}$.

Antes do manuseio dos materiais do laboratório, os bolsistas esclareceram brevemente como as substâncias a serem utilizadas foram preparadas e quais reagentes foram necessários para a preparação do experimento. Neste momento já se buscou problematizar que o registro de informações deve ser realizado com exatidão. Vale ressaltar ainda que o experimento proposto foi de fácil reprodução e baixo custo.

Durante a realização do experimento, os bolsistas problematizaram a prática, levantando questões aos alunos, para que eles fossem refletindo sobre o que estava acontecendo e pudessem organizar hipóteses ou explicações para os fenômenos observados. Segundo Delizoicov et al. (2009), é na problematização que os alunos sentem a necessidade de obter outros conhecimentos que ainda não detém.

Após a realização e discussão da prática os licenciandos explicaram os conceitos científicos envolvidos no experimento (Figuras 2 e 3 ).

$\mathrm{A}$ adição de amido ao primeiro béquer (onde não há vitamina $\mathrm{C}$ ) resulta na mudança de cor de marrom para azul escuro, resultante da formação de um complexo do iodeto com o amido. Ao se adicionar solução de iodo aos béqueres onde há a presença da vitamina $\mathrm{C}$ a mudança de cor só será observada quando toda vitamina $\mathrm{C}$ reagir com o iodeto presente na solução de iodo. Então, quanto mais vitamina $\mathrm{C}$ a solução contiver, maior será a quantidade de solução de iodo a ser utilizada. Quando toda vitamina $C$ for consumida os íons iodeto em excesso reagirão com o amido formando o complexo azul escuro.

As reações envolvidas (Figura 2) foram apresentadas e explicadas aos alunos (Figura 3).

A análise do questionário final, aplicado após as explicações dos bolsistas, revelou que a maioria dos estudantes entenderam os conceitos envolvidos na prática. Segue o relato de alguns estudantes, sendo selecionados àqueles que condizem com o pensamento da maioria do grupo.

Na primeira questão foi perguntado o que ocorreu quando se adicionou a solução de iodo ao béquer 1 ? $100 \%$ responderam corretamente:

\section{Estudante 16: "Vai formar um complexo de iodeto com amido"}

$\mathrm{Na}$ segunda questão os alunos tinham que responder o que ocorreu quando se adicionou a solução de iodo à solução contendo amido + sucos das frutas. $100 \%$ responderam corretamente:

Estudante 22: "Quanto mais vitamina C tiver mais iodo tenho que adicionar na solução"

Perguntou-se na terceira questão, qual das amostras eles achavam conter maior quantidade de vitamina $\mathrm{C}$ e por quê. $90 \%$ responderam corretamente: 
Estudante 2: "Vitamina C, porque precisou de maior número de gotas da solução de iodo"

Questionou-se então se houve degradação da vitamina C fervida, e $80 \%$ responderam corretamente:

Estudante 12: "Sim, porque menos gotas de iodo foram adicionadas".

Na quinta pergunta eles deveriam identificar as funções orgânicas do ácido ascórbico, ácido cítrico, etanoato de isobutila e ácido tartárico. 96\% dos discentes acertaram todas as questões, demonstrando que o conhecimento químico foi assimilado por eles.

O questionário inicial foi novamente aplicado, a fim de avaliar a evolução do conhecimento dos estudantes. Na primeira questão os alunos continuaram não citando a vitamina C como uma molécula orgânica, contudo $100 \%$ mencionaram sua importância para nosso organismo, como pode ser visto nas transcrições:

Estudante 1: "Ajuda na prevenção de doenças"

Estudante 4: "Possui propriedades que ajudam no nosso sistema imunológico"

Estudante 5: "Essencial para regular o metabolismo geral do nosso organismo"

Na segunda questão, $100 \%$ dos estudantes responderam que a vitamina C está presente nas frutas ou alimentos, e na terceira pergunta $100 \%$ responderam que a importância da vitamina C no organismo é referente ao aumento da imunidade e resistência.

Diferentemente do questionário inicial, os alunos passaram a conhecer a estrutura da vitamina $C$ e as funções orgânicas presentes em sua estrutura, sendo evidenciado pelos $96 \%$ de acerto à quarta questão, referente às funções orgânicas presentes na molécula do ácido ascórbico.

Observa-se que os estudantes aplicaram os conhecimentos adquiridos anteriormente para solucionar os questionários propostos, sendo este o objetivo do terceiro momento pedagógico.

Esta metodologia de ensino revelou um bom progresso no desempenho dos alunos, contribuindo para a aprendizagem de funções orgânicas. O uso de um tema do seu cotidiano, como a vitamina $C$, despertou um grande interesse sobre o assunto, levando a aprendizagem das funções orgânicas.

\section{Considerações finais}

É de suma importância que o aluno consiga correlacionar o conteúdo químico com o seu cotidiano. Assim a motivação, o interesse e consequentemente a aprendizagem pelos conceitos estudados em sala de aula se farão presente de forma mais efetiva.

216 DOI: Em andamento.

R. Bras. de Ensino de C\&T 
O PIBID, sub-projeto Química da UTFPR - Apucarana, vem buscando despertar nos licenciandos participantes do projeto, o interesse em estudar e propor novas metodologias de ensino de química, mais atrativas e interessantes, contribuindo assim na qualidade de sua formação como professor.

\section{Agradecimentos}

Á CAPES.

\section{Referências}

BORGES, S. A. Por que a Vitamina C é tão importante para o nosso corpo. Disponível em: <https://www.youtube.com/watch?v=CmKq78drbTg> Acesso em: 08 agosto 2014.

CARRASCOSA, J.; GIL-PÉREZ, D.; VILCHES, A.; VALDÉS, P. Papel de La actividad experimental em La educación científica. Caderno Brasileiro de Ensino de Física, v.23, n.2, p. 157-181, 2006.

DELIZOICOV, D.; ANGOTTI, J. A. A. Metodologia do ensino de ciências. São Paulo: Cortez, 1990.

DELIZOICOV, D.; ANGOTTI, J. A. A.; PERNAMBUCO, M. M. Ensino de Ciências: Fundamentos e Métodos. 3. Ed. São Paulo: Cortez, 2009.

FRANCISCO Jr. W. E.; FERREIRA, L. H.; HARTWIG, D. R. Experimentação Problematizadora: Fundamentos Teóricos e Práticos para a Aplicação em Sala de Aula de Ciências. Química Nova na Escola. n.30, p. 34-41, 2008.

GUIMARÃES, C. C. Experimentação no Ensino de Química: Caminhos e Descaminhos

Rumo à Aprendizagem Significativa. Química Nova na Escola. v.31, n.3, p. 198-202, 2009.

MALDANER, O. A. A formação inicial e continuada de professores de química:

professores/pesquisadores. Ijuí: UNIJUÍ, 2000.

MOREIRA, M. A; MASINI, E. A. S. Aprendizagem significativa: a teoria de aprendizagem de David Ausubel. 2a ed. São Paulo: Centauro Editora, 2006.

SILVA, A. L. S.; FERREIRA, L. A. G.; SILVA, R. R. A procura da vitamina C. Química Nova na Escola. n.2, p. 31-32, 1995.

Jéssica Guerreiro Martins. Licencianda em Química da Universidade Tecnológica Federal do Paraná, câmpus Apucarana. Bolsista do Programa Institucional de Bolsa de Iniciação à Docência (Pibid). E-mail: jessicamartins30@live.com 
Bruno Rafael Machado. Licanciado em Matemática pela Faculdade de Filosofia Ciências e Letras de Mandaguari, Licenciando em Química da Universidade Tecnológica Federal do Paraná, câmpus Apucarana. Bolsista do Programa Institucional de Bolsa de Iniciação à Docência (Pibid). E-mail: brunnoraffaell@hotmail.com

Alessandra Machado Baron. Bacharel e Licenciada em Química, mestre e doutora em QuímicaÁrea de concentração Química Orgânica pela Universidade Federal do Paraná. Professora da Universidade Tecnológica Federal do Paraná, câmpus Apucarana. E-mail: alessandrab@utfpr.edu.br

Lilian Tatiani Dusman Tonin. Bacharel e Licenciada em Química, mestre e doutora em QuímicaÁrea de concentração Química Orgânica pela Universidade Estadual de Maringá. Professora da Universidade Tecnológica Federal do Paraná, câmpus Apucarana. Coordenadora de área (Química) do Programa Institucional de Bolsa de Iniciação à Docência (Pibid) câmpus Apucarana. E-mail: liliandusman@utfpr.edu.br 